\title{
Recht als probleemoplossing?
}

Article $\cdot$ December 2017

DOI: $10.5553 / \mathrm{RdW} / 138064242017038002001$

CITATIONS

0

\section{3 authors:}

\section{Hilke Grootelaar}

Utrecht University

5 PUBLICATIONS 1 CITATION

SEE PROFILE

Wibo van Rossum

Erasmus University Rotterdam

32 PUBLICATIONS 32 CITATIONS

SEE PROFILE
READS

25

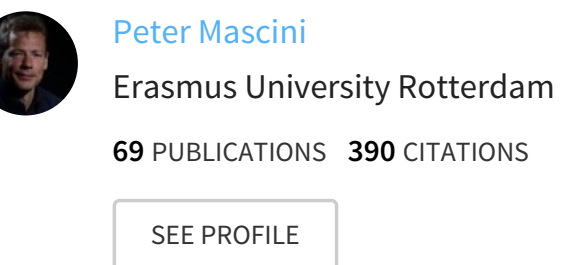

SEE PROFILE

Some of the authors of this publication are also working on these related projects:

Project $\quad$ Regulation \& enforcement View project

Enforcement of health and safety violations in an era of deregulation. Dilemmas for health and safety

Project regulators in the Netherlands. View project 


\title{
REDACTIONEEL
}

\section{Recht als probleemoplossing?}

\author{
Hilke Grootelaar, Peter Mascini \& Wibo van Rossum
}

Zowel het materiële als het formele recht biedt burgers allerlei instrumenten om geschillen juridisch te beëindigen. Dit kan worden bereikt door in juridische standpunten vertaalde strijdigheden te beslechten in overeenstemming met legaliteitsbeginselen. Maar is het recht ook voldoende toegerust om de oorzaken die aan conflicten van de strijdende partijen ten grondslag liggen te verminderen of op te lossen? Of breder, kan het recht een bijdrage leveren aan de aanpak van maatschappelijke problemen die de conflicten van de direct betrokken partijen overstijgen? En als het recht op zijn grenzen stuit bij het oplossen van onderliggende conflicten, zijn er dan alternatieve vormen van conflictbeslechting denkbaar die de grenzen van de rechtspraak kunnen overschrijden?

Over deze vragen is in de loop van de tijd verschillend gedacht. Zo signaleerde Max Weber in moderne samenlevingen een historische ontwikkeling van een formeel-rationele benadering van het recht naar een meer materieelrechtelijke benadering. De dominantie van formeel-rationeel legaal gezag, waarmee hij doelde op een neutraal stelsel van regels dat partijen in staat stelt om onderlinge conflicten op een vreedzame wijze uit te vechten voor een rechter die zich onafhankelijk opstelt boven de partijen, verschoof geleidelijk in de richting van een meer materieelrechtelijke benadering van het recht waarin het recht wordt ingezet als een instrument ter realisering van maatschappelijk wenselijke doeleinden, zoals de bescherming van de sociaal zwakkeren. ${ }^{1}$ Naarmate het recht meer als instrument wordt gezien om maatschappelijke misstanden tegen te gaan, wordt het minder neutraal en gaan rechters en beslissers meer casuïstisch te werk. Zo is de wetgever bijvoorbeeld afhankelijk geworden van de inzichten van rechters die de wetten moeten interpreteren in het licht van de steeds veranderende concrete omstandigheden van het geval. ${ }^{2}$ De door Weber geschetste ontwikkeling sluit goed aan op het door Nonet en Selznick ontwikkelde fasemodel. Zij voorzagen dat het recht transformeert van een instrument dat machthebbers gebruiken om hun particuliere belangen te behartigen, via het recht als een instituut dat boven de partijen staat naar een fase waarin het recht pragmatisch wordt ingezet om conflicten op een responsieve wijze op te lossen en zo een bijdrage te leveren aan de aanpak van sociale problemen. ${ }^{3}$ Naast deze ontwikkelingen waarin het recht van binnenuit transformeert, is ook het denken over de verhouding tussen de rechtspraak en andere vormen van conflictoplossing aan verandering onderhevig. Pleidooien voor de totale afschaffing van het strafrecht die opkwamen in de jaren zeventig 
van de vorige eeuw toen het geweldsmonopolie van de staat in toenemende mate ter discussie werd gesteld en steeds meer nadruk kwam te liggen op het belang van individuele vrijheid, zelfbepaling en het geloof in resocialiseerbaarheid van misdadigers - tijdens de zogenoemde 'silent revolution' - zijn bijvoorbeeld inmiddels nagenoeg geheel verstomd. ${ }^{4}$ Tegelijk zijn de alternatieve vormen van geschilbeslechting die in deze periode werden bedacht niet alleen verder ontwikkeld en geïncorporeerd in het strafrecht, maar zijn varianten hiervan ook doorgedrongen in het privaat- en bestuursrecht.

Ook tussen juridische regimes bestaan verschillen in de rol die aan het recht wordt toegeschreven in verband met de oplossing van geschillen en conflicten. In accusatoire regimes zijn de strijdende partijen in eerste instantie zelf verantwoordelijk voor het aandragen van bewijs voor hun standpunt en neemt de rechter een lijdelijke rol in, terwijl in inquisitoire regimes de rechter actiever bijdraagt aan waarheidsvinding op basis van geschreven teksten en rechtszittingen. Deze actievere rol geeft rechters meer ruimte om hun visie op het juridische geschil naar voren te brengen tijdens interacties met de strijdende partijen en zo de verwachtingen en gedragingen van de partijen te beïnvloeden. ${ }^{5}$ Deze actievere rol van de rechter impliceert overigens niet dat in accusatoire regimes minder hoge verwachtingen leven ten aanzien van de bijdrage die het recht kan leveren aan het oplossen van conflicten, aangezien accusatoire regimes doorgaans gecombineerd worden met ruimere mogelijkheden om wetgeving aan te passen op basis van afzonderlijke gevallen en lekenrechtspraak. ${ }^{6}$ Beide zijn bedoeld om het recht te laten aansluiten bij veranderingen die plaatsvinden in de samenleving en bij opvattingen over rechtvaardigheid die breed worden gedeeld. Beide regimes delen dus het uitgangspunt dat de rechtspraak meer moet zijn dan een op zichzelf betrokken systeem waarin de interpretatie van de formele regels is losgezongen van de conflicten die aanleiding zijn geweest tot het inschakelen van het recht. Ze verschillen alleen naar de mogelijkheden en beperkingen om deze verwachtingen te realiseren.

Verwachtingen over de rol van het recht verschillen niet alleen naar tijd en plaats, maar ook binnen bestaande rechtssystemen. Allereerst onder degenen die zelf rechtspreken. Welke rol zien zij voor henzelf weggelegd? Als van rechters verwacht wordt dat zij de formele kaders van het recht loslaten bij het oplossen van conflicten, verliezen zij dan niet hun onafhankelijkheid en onpartijdigheid? En als zij hun rol aanpassen, heeft dat dan wellicht onbedoelde gevolgen die de effectiviteit en legitimiteit van het recht aantasten? Veranderen aanpassingen die zijn bedoeld om recht meer te laten zijn dan een instrument voor de beëindiging van conflicten in juridische zin eigenlijk wel iets of vervullen ze eerder een symbolische rol? Te denken valt aan het spreekrecht voor slachtoffers. Is dit meer dan alleen een mogelijkheid voor slachtoffers om hun emoties te ventileren, terwijl tegenstellingen tussen partijen blijven bestaan of zelfs worden aangewakkerd? En

\footnotetext{
$4 \quad$ Mascini \& Houtman 2011.

5 Biland \& Steinmetz 2017.

6 Schneider 2001.
} 
hoe denken de partijen hier zelf over? Zitten zij te wachten op empowerment of willen zij een rechter die boven de partijen staat, omdat zij er zelf niet uitkomen? Ook specialisten zijn er niet over uit wat de rol van het recht als conflictoplossing is of zou moeten zijn. Onlangs pleitte mediator Jannie Dierx in een opiniestuk in het NRC Handelsblad voor meer mediation binnen het strafrecht, omdat een rechtszaak voor een slachtoffer een zware belasting en bovendien teleurstellend kan zijn. Een mediationgesprek met de dader kan dan bevredigender zijn. In tegenstelling tot het strafproces nodigt mediation bovendien niet uit tot escalatie, tot ingraven met juridische verweren en innemen van strategische procesposities, aldus Dierx. ${ }^{7}$ Ruth de Bock toont zich in haar oratie juist bezorgd over de verdringing van de rechtspraak door geschillencommissies, bestuursorganen en mediators. ${ }^{8}$ Doordat veel van die private geschilbeslechting vertrouwelijk is, blijft immers het lerende of disciplinerende effect ervan in de samenleving achterwege. Vandaar haar pleidooi voor een herijking van de rechter als bewaker van het publieke domein. Barendrecht, Van Beek en Muller beargumenteren in een recent rapport over de rechtsstaat dat de rechtspraak hoognodig op de schop moet om deze publieke rol goed te kunnen vervullen. Zij concluderen dat de burger weinig van het rechtssysteem, advocaten of de rechtspraak te verwachten heeft. Het recht is te veel van juristen en te weinig voor de burger. ${ }^{9}$ Hoogleraar internationaal arbeidsrecht, Klara Boonstra, deelt deze conclusie. Volgens haar lopen bijvoorbeeld flexwerkers die hun rechten claimen het risico daardoor te worden benadeeld. Het voor de rechter dagen van de werkgever waarvan zij afhankelijk zijn, verergert bijna als vanzelfsprekend het conflict. Ze schrijft: 'Het kost beide partijen veel geld, gaat met veel stress gepaard en een goede uitkomst is niet gegarandeerd. Een rechtsgang is eerder leed toevoegend, dan leed oplossend. ${ }^{10}$ Deze willekeurige voorbeelden van uiteenlopende standpunten die deskundigen innemen ten aanzien van de feitelijke of gewenste rol van de rechtspraak illustreren niet alleen dat het een actueel thema betreft dat de gemoederen danig bezighoudt, maar ook dat in veel opzichten de empirische kennis ontbreekt over het daadwerkelijk functioneren van de rechter en de effectiviteit daarvan. De vraag naar de mogelijkheden en beperkingen om het recht meer te laten zijn dan een instrument voor de juridische beslechting van geschillen staat centraal in dit themanummer van Recht der Werkelijkheid.

Jagtenberg en De Roo besteden in hun bijdrage aandacht aan de diffusie van een alternatief voor de juridische aanpak van familieconflicten. De oplossing van een familieconflict voltrekt zich hierin in verschillende fases, waarbij vooral familie en professionele jeugdhulpverlening betrokken zijn. Hun artikel over het familiegroepsplan laat zien dat het Nieuw-Zeelandse concept van de Familiy Group Conference (FGC) in Nederland vorm heeft gekregen als een 'recht op een familiegroepsplan' in de nieuwe Jeugdwet. Jagtenberg en De Roo laten zien hoe de betekenis van FGC verandert als het wordt getransponeerd naar andere jurisdicties.

$7 \quad$ Dierx 2017.

8 De Bock 2017.

9 Barendrecht, Van Beek \& Muller 2017.

10 Boonstra 2017. 
Smit, Bijleveld en Antokolskaia laten zien dat ook in gevallen waar geschillen wel voorgelegd móeten worden aan de rechter, het recht niet altijd een eenduidige oplossing biedt. In de complexe zaken waarbij sprake is van een beschuldiging van seksueel kindermisbruik blijken civiele rechters voor bijzonder lastige keuzes te staan over gezag, omgang en verblijf zonder dat zij zeker weten of er misbruik heeft plaatsgevonden. Smit c.s. laten zien dat de familierechters in hun onderzoek zich niet alleen zeer bewust zijn van de beperkte rol die het recht kan vervullen in het oplossen van onderliggende problemen, maar ook dat het recht deze zelfs kan verergeren. Volgens rechters wakkeren de beschuldigingen die in scheidingszaken worden geuit reeds bestaande onderliggende problemen aan en zijn de mogelijkheden van de rechter om deze problemen op een positieve manier te beïnvloeden zeer beperkt.

Van Rossum en Verschoof laten de verschillen zien in de wijze waarop civiele rechters hun eigen rol definiëren en hoe zij denken over het adresseren van het onderliggende conflict. Deze auteurs voerden een empirisch onderzoek uit naar de civiele comparitie van antwoord. Zij vinden weinig bevestiging voor de veronderstelde positieve bijdrage die een meer informele en op het conflict gerichte benadering levert aan een duurzamer oplossing van het probleem tussen partijen. Weliswaar zijn veel rechters geneigd om interventies te plegen om partijen nader tot elkaar te brengen en besteden zij veelvuldig aandacht aan het onderliggende conflict, maar deze inspanningen lijken er niet voor te zorgen dat vonnissen kunnen worden voorkomen doordat partijen overeenstemming bereiken over een schikking. Wel vinden Van Rossum en Verschoof aanwijzingen dat partijen zich hierdoor beter behandeld voelen.

Marseille, Van den Brink en Boekema focussen op de burger die zijn weg naar de rechter zoekt. Zij onderzochten burgers die binnen het bestuursrecht in hoger beroep zijn gegaan en dus al een procedure in eerste aanleg achter de rug hebben. De kwalitatieve uitspraken die hun kwantitatieve onderzoek illustreren, zijn een mooi voorbeeld van het rechterlijke onvermogen om conflicten op te lossen. Uitspraken als: 'Ik stond in mijn recht, alleen de juridische kant van de zaak is bekeken en niet de sociale' illustreren dat het recht niet altijd het meest geijkte instrument lijkt te zijn om het daadwerkelijke conflict op te lossen. Marseille c.s. laten bovendien zien dat onder rechtzoekenden, bij zowel winnaars als verliezers, veel ontevredenheid leeft over geschilbeslechting in het bestuursrecht, maar dat deze ontevredenheid geen afbreuk doet aan hun geneigdheid om rechtszaken aan te spannen. Dit roept de vraag op hoe dit kan worden begrepen. Is het recht laagdrempelig of zien partijen het als een principekwestie om alle mogelijkheden die het recht biedt uit te putten, ongeacht de uitkomsten die dit biedt?

Doornbos neemt de door Marseille en collega's geschetste problemen van burgers met de overheid als uitgangspunt voor haar artikel, waarin zij betoogt dat het perspectief van ervaren procedurele rechtvaardigheid tekortschiet om de problemen in het bestuursrecht het hoofd te bieden. Doornbos pleit ervoor om de focus meer op de inhoud en uitkomsten van juridische procedures te richten. Ook stelt zij de vraag hoe het valt te begrijpen dat burgers zo vaak problemen aan de bestuursrechter voorleggen, terwijl op voorhand duidelijk is dat de slagingskans zeer 
gering is en wat de overheid kan doen om de omvang van de categorie kansloze zaken terug te dringen.

Wever schrijft in Werk in uitvoering over de meest frequent gebruikte geschilbeslechtingsprocedure in Nederland: de bezwaarprocedure. Hierin blikt hij vooruit op het promotieonderzoek waarin hij ervaringen van professionele rechtshulpverleners met verschillende bezwaarschriftprocedures onderzoekt. Uit zijn bevindingen tot nu toe blijkt dat conflicten in de praktijk op een veel formelere wijze worden opgelost dan door de wetgever oorspronkelijk is bedoeld. Wever hoopt met zijn onderzoek meer inzicht te verschaffen in de relatie tussen de aard van een geschil en de kenmerken van de procedure waarmee dat geschil het beste zou kunnen worden behandeld.

In hun forumbijdrage nemen Coenraad en Verberk een positie in ten opzichte van de volgende stelling: 'Het oplossen van problemen van rechtzoekenden en samenleving behoort niet tot het domein van de rechter.' Beiden zijn het erover eens dat het idee dat een rechter bij het afdoen van een zaak oog moet hebben voor meer dan het juridische geschil inmiddels wel gemeengoed is. Hun gedachten lopen echter uiteen waar het gaat om de vraag of de rechter een rol kan vervullen in het oplossen van maatschappelijke problemen en zo ja, of dat ook wenselijk is. Terwijl Coenraad hierover terughoudendheid betracht, ziet Verberk wel mogelijkheden. Niet zozeer als een taak voor de individuele rechter, maar eerder voor de rechtspraak als organisatie.

We sluiten dit themanummer af met een recensie van het pas verdedigde proefschrift van kantonrechter Kim van der Kraats: De eigen(aardig)heid van de kantonrechter. In deze dissertatie gaat Van der Kraats onder meer in op de vraag of civiele rechters en kantonrechters een verschillende uitleg aan het procesrecht geven en wat daarvan de consequenties zijn voor de kwaliteit van het civiele proces.

Wat dit themanummer laat zien, is dat er geen helder onderscheid bestaat tussen recht als geschilbeslechting en conflictoplossing. Rechters zijn zich welbewust van de beperkte mogelijkheden die het recht hun biedt om onderliggende conflicten op te lossen en verschillen in de mate waarin zij ervoor open staan de rechtspraak een minder in zichzelf gekeerd systeem te laten zijn dat zich beperkt tot het toetsen van geschillen aan de wet. Tegelijkertijd lopen zij ook tegen beperkingen aan bij hun inspanningen om het recht van binnenuit te veranderen. Rechtzoekenden zien vele tekortkomingen aan het huidige systeem, maar dit belet hen vaak niet om alle rechtsmiddelen die hun ter beschikking staan te benutten, zelfs als ze in eerdere gevallen herhaaldelijk als verliezer uit de bus zijn gekomen. De pogingen om ontevredenheid te verminderen door procedures te verbeteren kunnen ertoe leiden dat nauwelijks een halt wordt toegeroepen aan zaken waarvan alle betrokkenen, behalve misschien de rechtzoekende zelf, weten dat ze kansloos zijn. En alternatieven die binnen een specifieke jurisdictie worden bedacht, krijgen een eigen rol en betekenis wanneer ze elders worden geïncorporeerd. Recht als conflictoplossing is geen gegeven, het is voortdurend in beweging en past zich aan veranderende maatschappelijke omstandigheden aan. 
Tijdens de productie van dit themanummer is John Griffiths overleden. Hiermee is een markante en bepalende wetenschapper voor de VSR verloren gegaan. Griffiths genoot zijn opleiding in de Verenigde Staten. Sinds zijn aanstelling als hoogleraar in de rechten in 1973 aan de New York University beschouwde hij zichzelf als rechtssocioloog. Hij werd als zodanig als hoogleraar in Groningen benoemd in 1977 en bleef dat tot zijn emeritaat in 2005. Gedurende zijn hele loopbaan heeft het samenspel tussen recht, rechtspraak en de samenleving centraal gestaan. Onderscheidend zijn zijn bijdragen aan rechtspluralisme en de sociale werking van recht. Griffiths heeft zich in de laatste fase van zijn wetenschappelijke loopbaan in het bijzonder gericht op medisch-ethische vraagstukken, met name dat van euthanasie. Nog dit jaar heeft Griffiths actief meegedacht over de koers van het tijdschrift. Onder de gastredactie van Keebet von Benda Beckman, Heleen Weijers en Albert Klijn zal Recht der Werkelijkheid volgend jaar een themanummer wijden aan de nalatenschap van het werk van John Griffiths. Hierin zal niet alleen bij zijn eigen werk worden stilgestaan, maar komen ook mensen aan bod die door het werk van Griffiths zijn geïnspireerd of die zich daartoe actief hebben verhouden.

\section{Referenties}

Barendrecht, J.M., K. van Beek \& S. Muller, Menselijk en rechtvaardig. Is de rechtsstaat er voor de burger?, Den Haag: HiiL 2017.

Biland, É. \& H. Steinmetz, 'Are judges street-level bureaucrats? Evidence from French and Canadian family courts', Law \& Social Inquiry 2017-2, p. 298-324.

Bock, R. de, De toekomst van de civiele rechtspraak, Amsterdam: Universiteit van Amsterdam 2017.

Boonstra, K., 'Wie sleept zijn baas nou voor de rechter?', NRC Handelsblad 23 en 24 september 2017.

Dierx, J., 'Nee, een rechtszaak biedt het slachtoffer geen troost', NRC Handelsblad 9 september 2017.

Mascini, P. \& D. Houtman, 'Resisting administrative tolerance in the Netherlands: A rightist backlash?', British Journal of Criminology 2011-4, p. 690-706.

Nonet, P. \& P. Selznick, Law and society in transition. Toward responsive law, New York, etc.: Harper \& Row Publishers 1978.

Schneider, C.E., 'Discretion and rules: A lawyer's view', in: K. Hawkins (ed.), The uses of discretion (p. 47-88), Oxford: Clarendon Press 2001.

Schwitters, R.J.S., Recht en samenleving in verandering. Een inleiding in de rechtssociologie, Deventer: Kluwer 2008. 